\title{
Entre imagens e textos: os manuais como práxis de saber
}

\author{
Between images and texts: manuals as a praxis of knowledge
}

\section{Iara Lis Schiavinatto}

Professora, Instituto de Artes/ Universidade Estadual de Campinas.

Rua Elis Regina, 50 - Cidade Universitária "Zeferino Vaz" 13083-854 - Campinas - SP - Brasil iaralis@uol.com.br

\section{Ermelinda Moutinho Pataca}

Professora, Faculdade de Educação/ Universidade de São Paulo.

Avenida da Universidade, 308 05508-040 - São Paulo - SP - Brasil ermelinda.pataca@gmail.com
SCHIAVINATTO, Iara Lis; PATACA, Ermelinda Moutinho. Entre imagens e textos: os manuais como práxis de saber. História, Ciências, Saúde Manguinhos, Rio de Janeiro, v.23, n.2, abr.-jun. 2016, p.551-566.

\section{Resumo}

Problematizamos uma série de gêneros textuais escritos durante o Iluminismo em Portugal, marcadamente entre 1720 e 1800, compreendendo-os na condição de manuais de saber, e apontamos alguns sentidos das imagens nesses escritos de ampla circulação no mundo lusobrasileiro.

Palavras-chave: Iluminismo; manuais; cultura visual; história das ciências; técnica.

\section{Abstract}

We investigate a series of writing genres from the Enlightenment in Portugal, especially between 1720 and 1800, comprehending them as manuals of knowledge, and we highlight some of the meanings of the images in these writings that were widely circulated in the Portuguese-speaking world.

Keywords: Enlightenment; manuals; visual culture; history of science; technique. 
A nalisamos aqui os manuais ou tratados elaborados, traduzidos e publicados em Portugal durante o Iluminismo, com foco para a produção, os usos e a circulação de imagens no período. Esse tipo de escrita se pretendia, por princípio, universal, tendo formas específicas de comunicação. A escolha dos manuais ou tratados se deu pelo fato de eles apresentarem com clareza os conceitos elaborados no período, a forte associação entre a teoria e a prática, esclarecendo tanto os aspectos epistemológicos quanto as técnicas e a aplicação tecnológica, utilizadas e valorizadas nas políticas no mundo colonial.

Muitos desses tratados foram estudados na historiografia (Schiavinatto, 2003; Pataca, Pinheiro, 2005; Pereira, Cruz, 2012), e nosso intuito não é esgotar a análise, mas sim caracterizar os manuais e como eles estão sendo abordados, assinalando o caráter documental das imagens e suas dimensões metodológicas. Consideramos os agenciamentos dessas imagens entre si e entre elas e os textos entrelaçados a seus usos e funções, contemplando a heterogeneidade dessa documentação, hoje espalhada em museus, bibliotecas, arquivos nacionais e estrangeiros.

A intensificação no uso das imagens no período porta um forte caráter de instrução, característico do ideário iluminista. Dessa forma, acreditamos que seria mais válido considerar o amplo quadro de relações entre arte, ciência e técnica nos círculos letrados do período para verificar como se davam as práticas disciplinares entremeadas por princípios técnicos comuns.

\section{Manuais, compêndios, tratados e instruções como gêneros textuais}

Notamos os manuais elaborados em Portugal, tanto no campo das ciências quanto das artes, investigando a maneira como foram produzidos, ou seja, da íntima associação entre a produção do conhecimento e a extrema necessidade de sua difusão por meio da produção de livros e da formação de novos discípulos em instituições como academias científicas, oficinas, aulas régias, universidades, museus e laboratórios. Consideraremos a intrínseca relação entre a produção do conhecimento, sua difusão e o desenvolvimento de estratégias de ensino tanto em termos teóricos quanto práticos.

A elaboração dos manuais se associava à formação e à atuação dos autores, suas visões de mundo, a disponibilidade de referenciais teóricos, a atuação prática e a formação de uma comunidade científica com expressões sociais, políticas e culturais. Vicente Coelho de Seabra (1788, p.IX) explicitou as características dos compêndios científicos: "A concisão, porém, a clareza, e a elegância dependem não só de um dom particular do espírito do escritor, mas ainda do seu modo de pensar, sobre que influem a educação, os mestres, os livros e a sua mesma nação".

Para nossa análise, escolhemos algumas obras que atualmente poderiam ser caracterizadas de modo genérico como manuais, mas que no século XVIII se desmembravam em gêneros textuais distintos e se caracterizavam de acordo com o público, a tradição literária, científica ou artística a que se filiavam. Com a finalidade de facilitar a leitura e atingir públicos abrangentes, o significado atribuído ao manual no período indica que seria um livro pequeno de trazer na mão (Bluteau, Silva, 1790). Assim, o formato do livro e sua praticidade demonstram sua facilitação de leitura. O gênero, que até a metade do século XVIII era utilizado preferencialmente para a divulgação de textos religiosos, passa a ser utilizado progressivamente para a instrução científica e artística. 
Associadas à necessidade de difundir a linguagem científica para seu desenvolvimento, premissa assumida desde o século XVII e intensificada durante o Iluminismo, a elaboração, a tradução e a publicação de livros que sintetizassem as discussões de cada área do saber tornaramse grande desafio para a comunidade científica. Próximo à proposição dos manuais, encontramos outros gêneros como os compêndios, métodos, elementos que, de acordo com Bluteau e Silva (1790), caracterizavam-se pela explanação sintética dos conceitos. O grande desafio da escrita seria, portanto, criar uma forma didática e sucinta de explicação do conhecimento por meio da "ordem sistemática, que apresenta o muito em pouco, e que prende as ideias, sem o que todo o estudo é difícil por depender de uma memória local" (Seabra, 1788, p.VIII).

Em associação aos princípios da ciência moderna, que se pretendia universalizante, generalista, sistemática, ordenada e sucinta com descrições em leis gerais, a elaboração de textos científicos passa já a assumir, nesse período, uma forma abreviada de escrita. $\mathrm{Na}$ elaboração dos compêndios, os autores precisavam ultrapassar a compreensão dos conceitos de sua especialidade. A grande dificuldade consistia em fazer uma explicação com extrema concisão. Seabra (1788, p.VII) advertia: "Não basta ter conhecimento de todos os ramos de qualquer ciência, para nos autorizarmos a fazer um compêndio; é preciso um trabalho talvez o maior, que consiste em examinar as relações, semelhanças, diferenças, e a causa disto entre parte e parte, entre indivíduo e indivíduo, da mesma ciência".

Os tratados eram caracterizados como gênero de forma bastante distinta e se referiam a dissertação, opúsculo sobre algum assunto (Bluteau, Silva, 1790). Dessa forma, os tratados eram, em sua maioria, publicações inéditas, elaboradas para abordar determinado tema em profundidade maior que a dos compêndios. Próximo a essa categoria, os princípios se caracterizavam como obras fundamentais que revelavam as teses originais ou "o começo, a primeira obra ou trabalho que se faz" (Bluteau, Silva, 1790). Vicente Coelho de Seabra (1788, p.IX), em Elementos de química, explicava ainda a distinção entre tratados e compêndios: "O método, ordem, concisão, clareza, e elegância são as condições necessárias para a perfeição de qualquer tratado. Estes requisitos podem-se facilmente achar numa obra que trate somente de um objeto ou ramo de qualquer ciência; mas é dificílimo abrangê-los num compêndio, onde se devem compreender todos os ramos e indivíduos pertencentes àquela doutrina".

A necessidade de divulgar a linguagem científica para a população também foi explicitada por Brotero (1788) em seu Compêndio de botânica, privilegiando a divulgação de uma obra em português para leitores que não soubessem latim. Brotero (1788, v.1, p.VIII) distinguiu os tratados e os compêndios, demonstrando a completude de sua obra com o seguinte argumento: "Não receio atualmente de assegurar que, sem embargo de ser um compêndio, o leitor não achará tratado algum elementar de botânica mais completo de quantos se tem até agora publicado".

A distinção entre os gêneros se dava tanto na escrita quanto nas dimensões dos livros, elementos gráficos e ilustrações. Dessa forma, devemos analisá-los de forma distinta, considerando as imagens em associação intrínseca com os textos e os recursos editoriais. Para facilitar nossa análise, agruparemos as obras analisadas em dois grandes blocos: manuais que se caracterizam pela escrita sumária e didática; tratados como obras mais abrangentes e com mais profundidade na definição dos conceitos. 
Um último gênero que gostaríamos de tratar aqui é o das instruções. Com um caráter didático mais acentuado, as instruções constituíam "apontamento, regimento que se dá a alguém para se reger por ele" (Bluteau, Silva, 1790). Esses textos se destinavam, portanto, a direcionar e disciplinar práticas científicas, como é o caso das instruções de viagens que já foram amplamente tratadas por historiadores das ciências (Schiavinatto, 2003; Kury, 1998; Brigola, 2003, 2012; Pataca, Pinheiro, 2005; Pataca, 2006, 2011; Vaz, 2002). As instruções também foram adotadas para a divulgação de novas tecnologias, especialmente na agricultura visando à introdução de novos gêneros agrícolas nas colônias e ao desenvolvimento de sua cultura.

Nesses compêndios, o uso de imagens e elementos gráficos que auxiliem na compreensão dos conceitos é bastante frequente, tornando a função didática a característica em comum a todas as imagens dos manuais. Porém, as imagens assumiam funções de acordo com a área do conhecimento a que se relacionavam. Na botânica ou na engenharia, o desenho era intrínseco à produção de conhecimento, e os manuais analisados apresentavam longas digressões sobre as técnicas e os padrões de sua produção e utilização. Já em áreas como a química, a física ou a álgebra, em que não há necessidade de descrever com precisão os objetos de investigação, o desenho aparece raramente para explicitar e explicar conceitos que não apresentam a visualização.

Assim, assinalamos as diversas funções das imagens em associação aos temas de investigação delineados pelas questões epistemológicas de cada área do conhecimento. Considerando que as práticas científicas e artísticas são mais abrangentes que apenas o domínio conceitual, sendo conformadas pelas dimensões técnicas, analisamos, ainda, o modo como os desenhos demonstram as práticas, explicitadas em instrumentos, montagens, máquinas, construções e processos fabris. A associação entre teoria e prática, demonstrando a práxis científica e artística, foi amplamente revelada nos tratados. Assinalamos as funções comunicativas dos desenhos, inseridas na cultura textual e editorial do período.

\section{Os tratados de engenharia militar}

Os tratados de engenharia militar datam do Renascimento, havendo uma circulação da tratadística, dos autores aos textos, dos conceitos e das práticas entre as cidades italianas e a monarquia portuguesa que abrangeu as áreas de Conquista. Há, contudo, um impulso renovador no conhecimento da engenharia militar no governo de dom João V quanto às técnicas de levantamento arquitetônico, topográfico, corográfico e geográfico. Muda a representação no papel que passava a situar a engenharia militar no campo das ciências. Essa mudança asseverava a figura do engenheiro militar como ocorria desde o século XVII.

A engenharia militar se tornava uma ciência do conhecimento aplicado da matemática que se entremeava ao saber geográfico, ao domínio militar e a uma dimensão estética, explicitados por excelência na publicação de dois importantes tratados que evidenciam a força da ciência do desenho: Tratado do modo o mais fácil e o mais exato de fazer as cartas geográficas, assim da terra como de mar, e tirar as plantas das praças, cidades e edifícios com instrumentos e sem instrumentos para servir de instrução à fabrica das cartas geográficas de história eclesiástica, e secular de Portugal (Fortes, 1722) e O engenheiro português (Fortes, 1728-1729), ambos de 
Manoel de Azevedo Fortes - membro da Academia Real de História e responsável pelas questões geográficas das Províncias do Reino e Conquistas. O autor conta que retira dos autores estrangeiros e de sua experiência seu método fácil, ensinando-o a engenheiros e curiosos, transmitindo-o com clareza e precisão. Refere-se a um todo previsto e definido pelo conhecimento derivado dos estudos e da larga e variada experiência, que consumia seu tempo para encontrar os nexos comuns. Assim, o método consiste numa síntese que deve ser, por natureza, útil e aplicativa. Manoel de Azevedo Fortes (1722, p.199-200) afirmou:

Tenho dado neste tratado (segundo me parece) uma ideia completa do modo de fazer as cartas geográficas, e tirar as plantas topográficas de qualquer país, e de qualquer lugar particular, com a mais miúda individuação de tudo o que pode contribuir para o melhor acerto; porque escrevo para os principiantes, aos quais poderá ser útil, que não poderiam adquirir sem muito trabalho, largo tempo, e repetidas experiências. Os que o sabem, e o acharem defeituoso, farão grande serviço ao público, se o quiserem emendar, e os que totalmente o acharem inútil, ninguém os obriga a que o leiam.

Esses tratados eram usados e difundidos na cadeia produtiva das edificações e dos traçados urbanos no império português, instruindo também os mestres de ofício nos canteiros de obra (Bueno, 2012). Em simultâneo, eram lidos, interpretados, copiados, usados nas academias militares que formavam engenheiros militares - um homem de ofício polivalente a serviço da arquitetura de poderes da monarquia portuguesa ultramarina. Esses tratados eram concebidos pelos mestres dessas academias como apostilas de orientação dos alunos. Tais tratados foram muito eficientes na produção e na disseminação de saberes militares, cartográficos, urbanísticos, geográficos pelo mundo português. O Engenheiro português abordava a aritmética, os elementos euclidianos, a geometria prática, a trigonometria, a fortificação, o ataque e a defesa de praças, o método de tirar plantas e cartas topográficas com seus perfis, elevações e fachadas e o modo de as desenhar, além da artilharia. Falava de desenho, geometria, aritmética, óptica e astronomia, discorrendo sobre tudo que dissesse respeito à prática da profissão da engenharia militar com os instrumentos (prancheta, bússola, estojo de matemática, pedômetro, telescópio, relógio de pêndula, quadrantes, teodolitos entre outros) disponíveis e os modos de empregá-los e, por outro lado, abordava como proceder sem instrumentos, por exemplo, numa medição topográfica.

Esses tratados também embasaram os planos de urbanização e demarcação territorial na bacia amazônica e na capitania do Mato Grosso fundada em 1748 (Araújo, 2012), levados a cabo pelo capitão-general, governador do Grão-Pará e plenipotenciário das demarcações no Norte Francisco Xavier de Mendonça Furtado, irmão de Sebastião José de Carvalho e Melo, e pelo governador dom António Rolim de Moura, respectivamente. Fundamentaram o processo de demarcação territorial dos tratados de Madri (1750), El Pardo (1761) e Santo Ildefonso (1777), acarretando na construção do território do Brasil em fins do século XVIII, elaborado pela diplomacia, pela ação militar, pelos saberes científicos, todos entremeados (Magalhães, 2009). Assim, o próprio território se erigia num artefato, pois não se constituía em um dado da natureza. Só na cartografia a América portuguesa se torna apreensível como uma realidade geográfica e jurídica (Kantor, Bueno, Ferlini, 2009). Já o conde de Ericeira, fundador da Academia de História, na "Aprovação" do tratado de Azevedo Fortes de 1722 (p.III), esclarecia que a história dependia das cartas geográficas, e os "Mapas adornam com 
tanta utilidade os seus livros, que é preciso [que] haja um método uniforme, para que possam delinear-se os terrenos, e praças, que hão de descrever-se com medidas conformes; e ajustadas". Ele alinhava geografia e história por meio da cartografia e demandava a uniformização da imagem e do método de sua fatura.

Os tratados alicerçaram os estudos cartográficos e a cartografia em geral nesse período, sendo que no século XVIII a cartografia perdeu definitivamente seu teor decorativo em favor da precisão científica. O Tratado do modo mais fácil ... de fazer as cartas geográficas (Fortes, 1722) alinhava as convenções e os códigos de representação ao modo de riscar e aquarelar as plantas militares, detalhando o processo de fatura da coloração e as tipologias dos lugares indiciados por símbolos gráficos, cores, distâncias, alturas e profundidades. Por sua vez, a coloração sinalizava a geografia local no mapa, como explicava Fortes em "Receita de aguado de rios" nessa obra. Esse ensinamento de forte teor estético homogeneizava um importante elemento discursivo da cartografia ao tempo que transmitia esse conhecimento para estudantes que atuavam depois em diversas partes do Império transoceânico português nas expedições demarcatórias, de naturalistas, nas fortificações, na fundação e urbanização de vilas e cidades. No conjunto, esses tratados concorreram para ordenação integrada dessas atividades coloniais, agenciando-as e estabelecendo uma paisagem geográfica e territorial semelhante nas terras do monarca (Bueno, 2011).

Esses tratados mostram um projeto intelectual que articulava conhecimento da realidade e ação sobre ela, por meio de uma linguagem própria vincada por convenções e códigos em um processo de uniformização de saberes de engenharia militar. Tornaram-se uma referência fundamental na formação desses profissionais, sendo estudados durante a formação e consultados in loco e no decorrer da obra e da vida. Eles constituíam um sistema coerente ordenado de saberes sem nomear ou levantar polêmicas no próprio texto, sendo composto com cuidado, na medida em que entremeavam tais saberes de longa tradição, por exemplo, os elementos euclidianos, com uma estética agradável aos olhos, que suscitava admiração e aprendizado só de ver. Esse tipo de tratado, usado em larga escala em academias militares e nos canteiros, nos terrenos virgens ou pouco conhecidos por parte da empreitada colonial, pautavase em conceitos fundamentais e prescrevia métodos de largo alcance. Daí a importância do desenho (Bueno, 2011) em suas três dimensões de projeto, linguagem e forma como um ideário de saber que parece simples e que era altamente transmitido, mas que, no entanto, ancorava-se num conjunto de saberes culto e refinado. A imagem nesses tratados tornavase um lugar de conhecimento buscando uniformizar as representações do espaço e mesmo a intervenção numa área, moldando-a como território ou riscando-a com vilas e cidades. Há nesses tratados dimensões variadas da imagem: é descritiva, ilustrativa, útil e agradável, filha de um método que se quer uniforme e capaz de ensinar procedimentos e técnicas a instruir de modos e graus diversos homens de ofício.

\section{Elaboração de manuais teóricos para o ensino}

A reforma do ensino na Universidade de Coimbra ensejou a elaboração e a tradução de compêndios para a formação teórica e prática preconizada nos princípios das ciências modernas 
então implementadas. A publicação dos textos participava do projeto de desenvolvimento científico e tecnológico que atingia tanto a metrópole quanto as colônias.

Essa abrangência aparece em Elementos de química de Vicente Coelho de Seabra (1788), publicado quando o autor era apenas estudante de filosofia natural na Universidade de Coimbra. O vínculo com o Brasil e a exaltação de seu sentimento patriótico por meio do desenvolvimento das artes, das ciências, da agricultura e do comércio aparecem na dedicatória da obra aos estudantes da Sociedade Literária do Rio de Janeiro que se instruiriam pela compreensão da linguagem da química moderna.

Baseado na observação e na experimentação, o desenvolvimento da química, para o autor, era proporcionado por comparações que permitiam a classificação das substâncias, especialmente de suas similitudes e diferenças. Assim, os elementos gráficos apresentados na obra nos demonstram operações conceituais, com possibilidades de interpretação simbólica sobre a afinidade - proximidade ou distanciamento entre as substâncias. O compêndio era uma síntese das obras dos químicos franceses modernos, como Fourcroy, Lavoisier e Bertholet, que introduziram na química os princípios da física newtoniana, como o universalismo, a precisão matemática e a quantificação. Nesse sentido, as representações feitas pelo autor auxiliam o leitor a perceber a proporcionalidade de quanto uma substância tinha afinidade com a outra, como podemos ver na Imagem 1. Além disso, as representações imagéticas mostravam novos instrumentos, aparelhos e montagens associados à experimentação química que seriam essenciais para a difusão dessa ciência (Imagem 2).

No caso da botânica, o caráter descritivo das imagens é muito mais explícito e pretende mostrar os caracteres visuais, essenciais para a identificação e classificação vegetal que se pretendia no período. $\mathrm{O}$ uso das imagens era intrínseco às práticas botânicas, especialmente na descrição visual dos caracteres dos vegetais. Para apresentarmos aqui o caráter descritivo das imagens, recorremos ao Compêndio de botânica de Brotero (1788), em especial ao primeiro volume no capítulo que disserta sobre a descrição. Em tom de síntese e para esclarecer ainda mais a linguagem botânica, no segundo volume Brotero escreveu um "Dicionário botânico" que se associa diretamente às explicações do primeiro, complementando sua compreensão. No verbete "descrição", percebemos de forma muito sintética a relação entre as imagens e as palavras: "Uma perfeita descrição deve mencionar com clareza, e termos próprios todas as partes da frutificação, hábito externo e interno, em uma palavra, tudo o que diz respeito à completa história natural da planta, ajuntando-lhe uma fiel estampa" (Brotero, 1788, v.2, p.178). Os desenhos, quando fossem bem elaborados e com gravura em cobre, que garantia a representação de pequenos detalhes das plantas, poderiam assegurar a precisão para a descrição botânica, que não se associa à matemática:

Como a botânica não pode demonstrar a fé dos caracteres por um rigor matemático, e que é muitas vezes difícil de poder reconhecer algumas plantas pelos sinais característicos, que delas se dão; os botânicos costumam ajuntar tanto às descrições analíticas como históricas as estampas das plantas de que tratam, suprindo por este modo aos defeitos que há nas ditas descrições. Esta reunião faz o estudo dos vegetais fácil, e agradável; mas é preciso que as estampas sejam gravadas em cobre como deve ser. A estampa de uma planta é um monumento que a deve transmitir à posteridade, e por isso deve ser fiel; para ser fiel é preciso que o pintor e abridor sejam botânicos, ou ao menos que um botânico presida a toda a obra da estampa (Brotero, 1788, v.2, p.360). 


\section{4}

\section{ELEMENTOS}

§. 24. A Affinidade dobrada he quando hum compolta $a b$ dos dous corpos $a$, e $b$, naó póde fer decompolto por hum terceiro $c$, nem por hum quarto d feparadamente, mas unindofe-lhe hum compofto c $d$ do terceiro, e quarto corpo : ha logo huma decompofiçaó mutua. Para concebermos como fuccede efte fenomeno, reprefentaremos eftes compoltos delte modo.

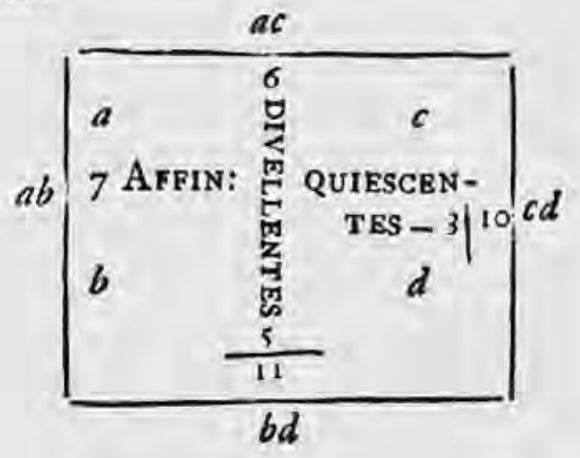

Imagem 1: Representação sobre as afinidades químicas (Seabra, 1788, p.14)

\section{APPARELHO PNEUMATO-CHIMICO \\ COM BALAÖ.}

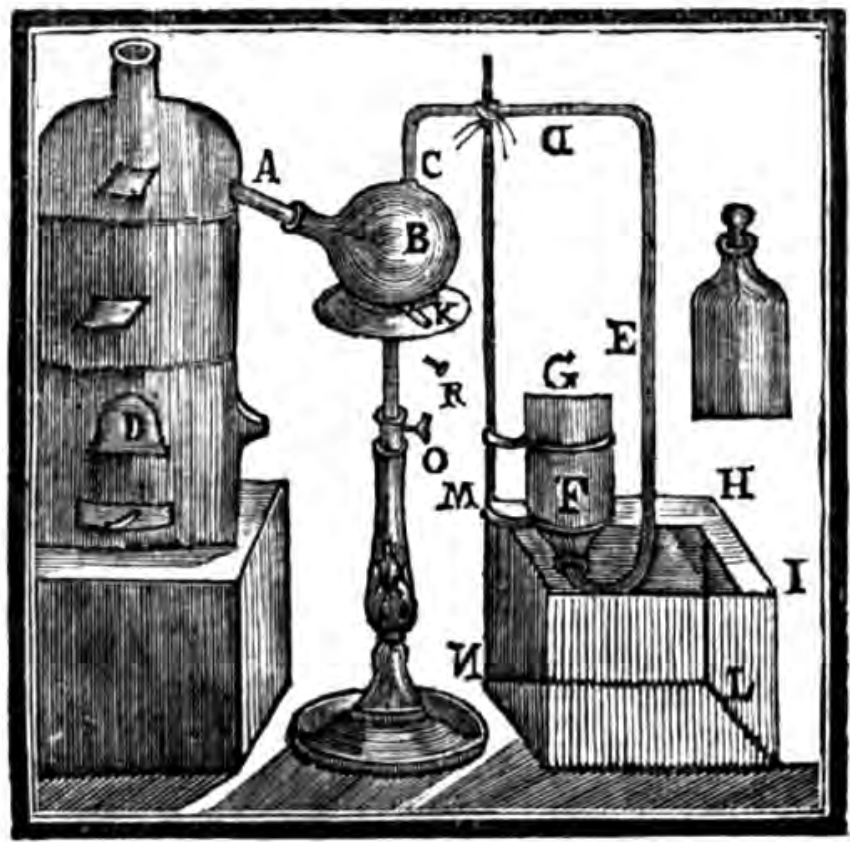

Imagem 2:"Aparelho

pneumatoquímico com balão".

Montagem experimental sobre

combustão com oxigênio

(Seabra, 1788, p.489) 


\section{As instruções de viagens: dimensões técnicas e instrumentais}

Em relação ao exercício das viagens e para a orientação dos viajantes sobre as observações e investigações a serem realizadas in loco, destacamos o papel das instruções de viagens. Há variações internas nas instruções endereçadas aos naturalistas, desenhadores, administradores coloniais, médicos, matemáticos, engenheiros. Contudo, notamos o enorme esforço de sistematização da experiência, dos registros da viagem, da sua descrição, dos objetos vistos, coletados, preservados e remetidos e suas necessárias correlações com os textos enviados. Os objetos cuja catalogação e cuidado de preservação iniciavam-se no sítio visitado preferencialmente integrariam uma coleção que referenciava aquele lugar. Imperava uma necessidade de ordenar a experiência da viagem. Isso significava entremear a catalogação dos objetos, sua preservação, a montagem dessa coleção e sua continuidade, a observação in loco, e, posteriormente, o trabalho prosseguiria no horto botânico, no jardim, no museu ou no laboratório em Lisboa e em Coimbra.

O naturalista dedicava-se ainda à descrição da viagem e aos seus resultados, à impressão dos textos e das imagens, somando-se a isso a constante recolha de outras descrições e memórias, fossem monográficas ou de caráter mais geral, sobre os temas estudados. Todos esses objetos, práticas, textos, imagens deveriam estar articulados num todo coerente. No conjunto, os manuais e as expedições concorriam para a consolidação de uma lógica, um novo paradigma disciplinar, portanto metodológico e eivado de práticas, que unia o museu, o jardim, o modelo taxonômico lineano e as peregrinações de caráter imperial, tão queridas por Lineu, como admitira em sua correspondência a Vandelli (Scarano, 2008).

Nesse contexto, observamos que as imagens que acompanhavam as instruções tinham uma função predominantemente técnica e instrumental na orientação do exercício das viagens. Observamos um predomínio de imagens que instruíssem, com extrema clareza, como os objetos deveriam ser coletados, preparados e transportados até chegar em perfeitas condições aos museus metropolitanos. Apresentamos dois exemplos dessas instruções: uma tábua com a representação dos instrumentos que deveriam ser utilizados para coletar os produtos de história natural e de seu transporte (Imagem 3).

O gentleman Thomas Pennaut se correspondia com Vandelli. Era um naturalista incansável, segundo Brigola (2012), que ajudou a popularizar e a promover a história natural nas ilhas Britânicas. Sua atuação e sua trajetória expõem a face amadora, não menos eficiente, da história natural que adentrou o cotidiano letrado e diletante, conquistando, por meio dos relatos, das imagens, dos objetos, dos hortos, dos jardins, uma nova camada de leitores, leitoras e praticantes. Ora, espaços de sociabilidade, textos, objetos e imagens eram manejados na divulgação e na recepção da história natural. Logo, esses manuais, escritos, ilustrações, objetos coletados, preservados, remetidos, decorrentes das viagens funcionavam dentro de uma complexa teia de relações internacionais e estabeleciam entre si uma série de agenciamentos associados a lugares visitados e estudados, que se tornavam, por seu turno, uma nova ordem de lugares destinados ao saber científico. 


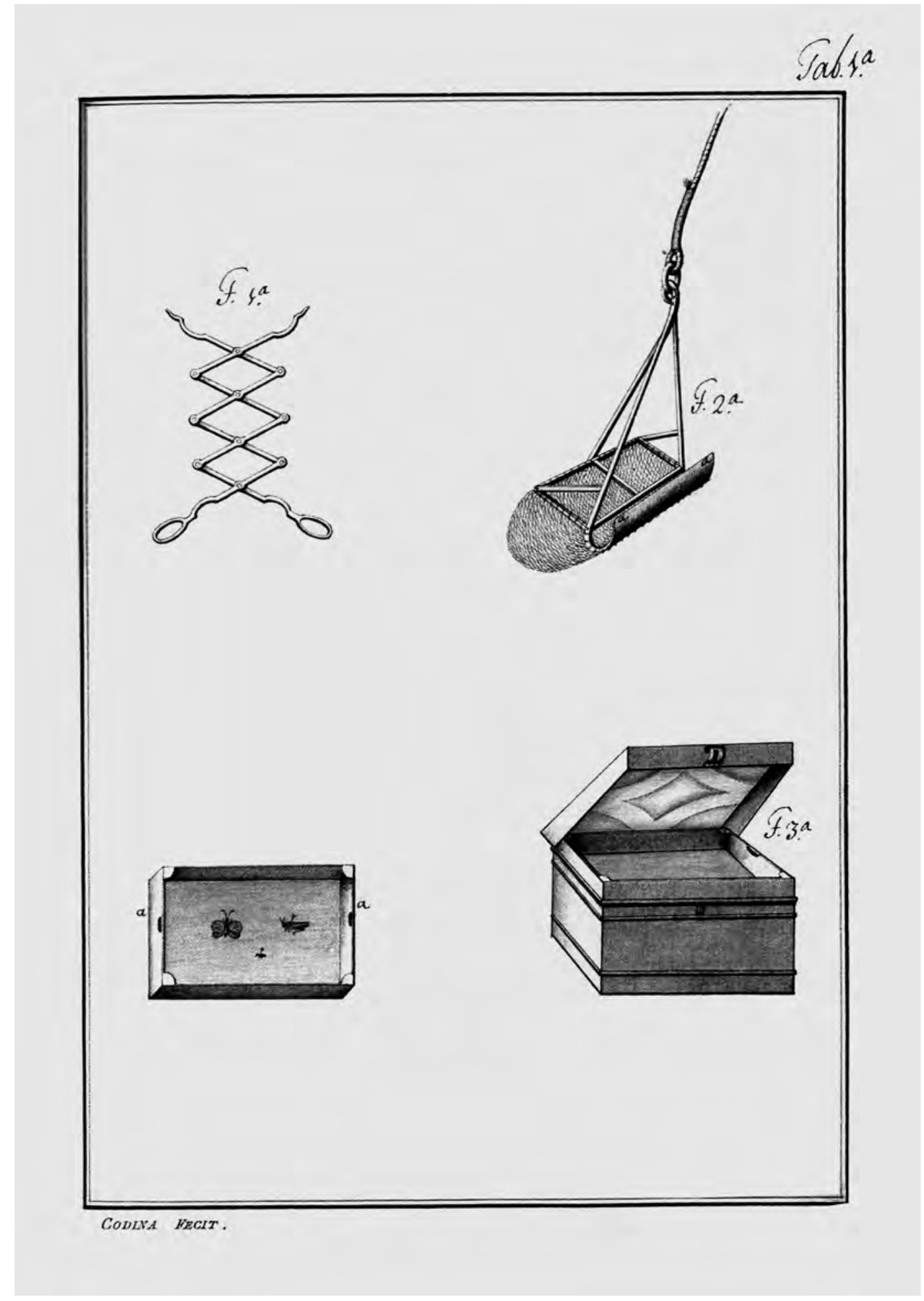

Imagem 3: Instrumentos utilizados para a coleta e o transporte de materiais (Ferreira, 1781) 


\section{Manuais de ciências e artes: Arco do Cego}

No geral, pode-se assinalar que a leitura de manuais e tratados delineavam sociabilidades mundanas, mercantis, científicas e artísticas no mundo português letrado a normatizar desde as relações de corte, a educação de menino, o papel do comerciante até o ensino do desenho. Dentre os 83 títulos conhecidos e publicados entre 1799 e 1801 pela Casa do Arco do Cego em Lisboa, dirigida por frei José Mariano da Conceição Veloso, nascido em Minas Gerais, vários eram manuais que tratavam da economia agrícola à história natural, das belas artes às obras náuticas. Dessas 83 publicações, 38 eram ilustradas, superando em muito a proporção de publicações ilustradas da Imprensa Régia (Faria, 1999).

O projeto editorial capitaneado por frei Veloso privilegiava os manuais, as traduções, a reprodução e cópia de imagens gravadas, sabendo-se que o recurso à imagem era um instrumento didático que se expandia ao longo do século XVIII no mundo português, da Real Academia de História à Imprensa Régia. O Arco do Cego concorreu para tanto a ponto de ser depois incorporado pela Imprensa Régia.

Os títulos das obras muitas vezes indicavam sua condição de texto destinado a funcionar como uma leitura de caráter instrumental, intitulando-se descrição, compêndio, ensaio, coleção, tratado, cartas, manual prático. No Arco do Cego, houve uma escolha editorial pela publicação de textos que abordassem as imagens e sua feitura como se via no Catálogo das obras de desenho ou no Tratado de gravura de Abraham Bosse (1801), traduzido por José Joaquim Viegas Menezes; A ciência das sombras relativa ao desenho, de M. Dupain, traduzido por frei Veloso; A arte da pintura de Charles Alphonse du Fresnoy (1801); Princípios da arte da gravura e $O$ grande livro de pintores, ambos de Gérardo Lairesse; e $O$ meio de se fazer pintor em três horas. Ou seja, havia textos traduzidos a tematizar as imagens.

Ademais, no corpo dos livros, as imagens vinham interligadas aos textos. Elas tinham uma forte carga informativa, ilustrativa, com fins de instruir, além de adornar os textos. Na Descrição da árvore açucareira e da sua utilidade e cultura de Hipólito José da Costa (1800), depois editor do Correio Brasiliense, a imagem mostra a planta com folhas largas, tronco cortado, cacho e, embaixo à direita, indica sua utilidade porque abastece um jarro, sugerindo seu rendimento. Enquanto em Fitografia de Brotero (1800), Coleção de memórias sobre quássia amarga e no Compêndio sobre a cana, ambos traduzidos pelo frei Veloso (1801), Observações sobre a propriedade da quina do Brasil, traduzido por José Ferreira da Silva (1801), aparecem pranchas que demonstram o processo de floração de uma planta estudada. As imagens completavam os textos, e vice-versa, bem como simplificavam, porque sintetizavam processos de trabalhos, apresentação, montagem e usos de instrumentos coadunando-os com os trabalhadores (Imagem 4). Na Figura 1, assim nomeada na Imagem 4, os trabalhadores aram a terra; na Figura 2, semeiam; e na Figura 3, colhem. Cada instrumento é marcado e reconhecido na última banda abaixo dessa figura, sendo que, dentro dela, cada instrumento aparece montado e desmontado de forma a explicitar suas partes e seu todo, bem como seu uso correto por parte desse trabalhador, a princípio um escravo caracterizado pelas vestes, pés descalços, coloração e riscado da superfície da pele. A imagem designa cada momento de uso desses instrumentos e as tarefas com as quais se coadunavam considerando essa relação intrínseca com o corpo do trabalhador para seu funcionamento. Essa linguagem visual acerca dos instrumentos aparece 


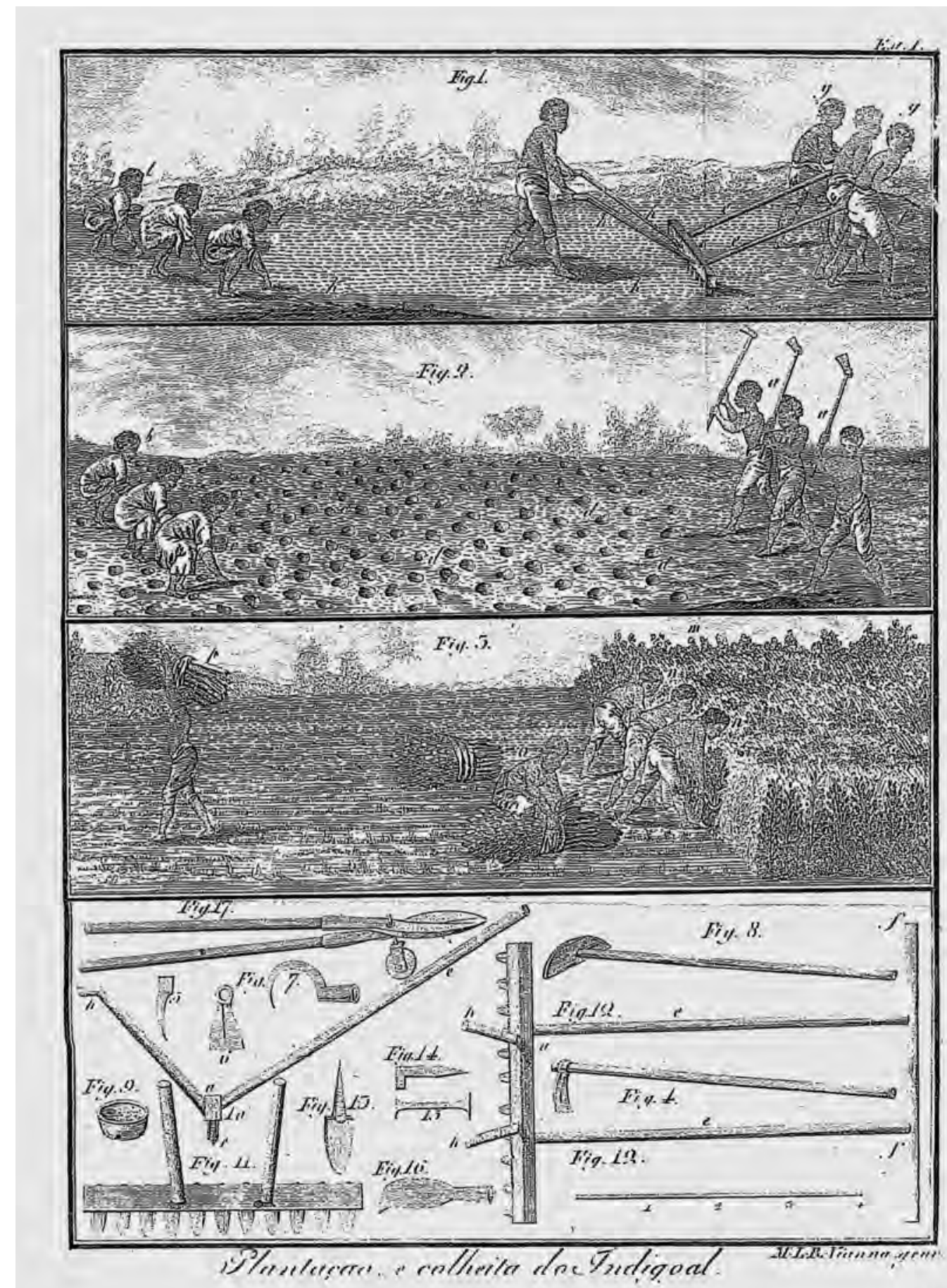

[137]

Imagem 4: "Plantação e colheita do indigoal", estampa gravada por M.L.R. Vianna e publicada por José Mariano da

Conceição Veloso em O fazendeiro do Brasil, t.2, parte 2, "Tinturaria", estampa 9, 1798-1806 (Campos et al., 1999, p.237) 
no Plano da reforma das moendas, e picadeiro dos engenhos de açúcar por Jerônimo Vieira de Abreu (Imagem 5), sendo o desenho tirado no Rio de Janeiro sob ordens, no mínimo, de Jerônimo Vieira de Abreu, deputado da Mesa de Inspeção dessa cidade que propunha a reforma das fornalhas. Novamente, as peças e os espaços são indicados por códigos e convenções que também perpassavam a linguagem visual da engenharia militar.

Nas estampas de $O$ engenheiro português de Manoel de Azevedo Fortes (1728-1729), os instrumentos são apresentados em conjunto e poderiam ser usados juntos para uma mensuração ou cada um por si; todavia a prancheta circular moderna era desmontada para pontuar sua ordenação, conexões, encaixes que ligavam bússola, tripé, circunferência graduada, óculo fixo e móvel, e, em paralelo, mostrava seu uso para o levantamento topográfico feito por triangulação com vários terrenos, com várias distâncias e alturas. Havia interesse nesses letrados em dispor os mecanismos internos desses instrumentos e máquinas. A imagem buscava agradar o espectador/leitor e, imediatamente, o instruía.

Os textos do Arco do Cego e da engenharia militar comentados partilhavam uma linguagem visual comum que previa para a imagem um sentido ilustrativo, instrutivo, altamente técnico e útil que poderia ser lido e usado durante a formação de diversos sujeitos sociais, do engenheiro ao curioso e no transcorrer do trabalho no campo, nos espaços de produção, in loco abrangendo

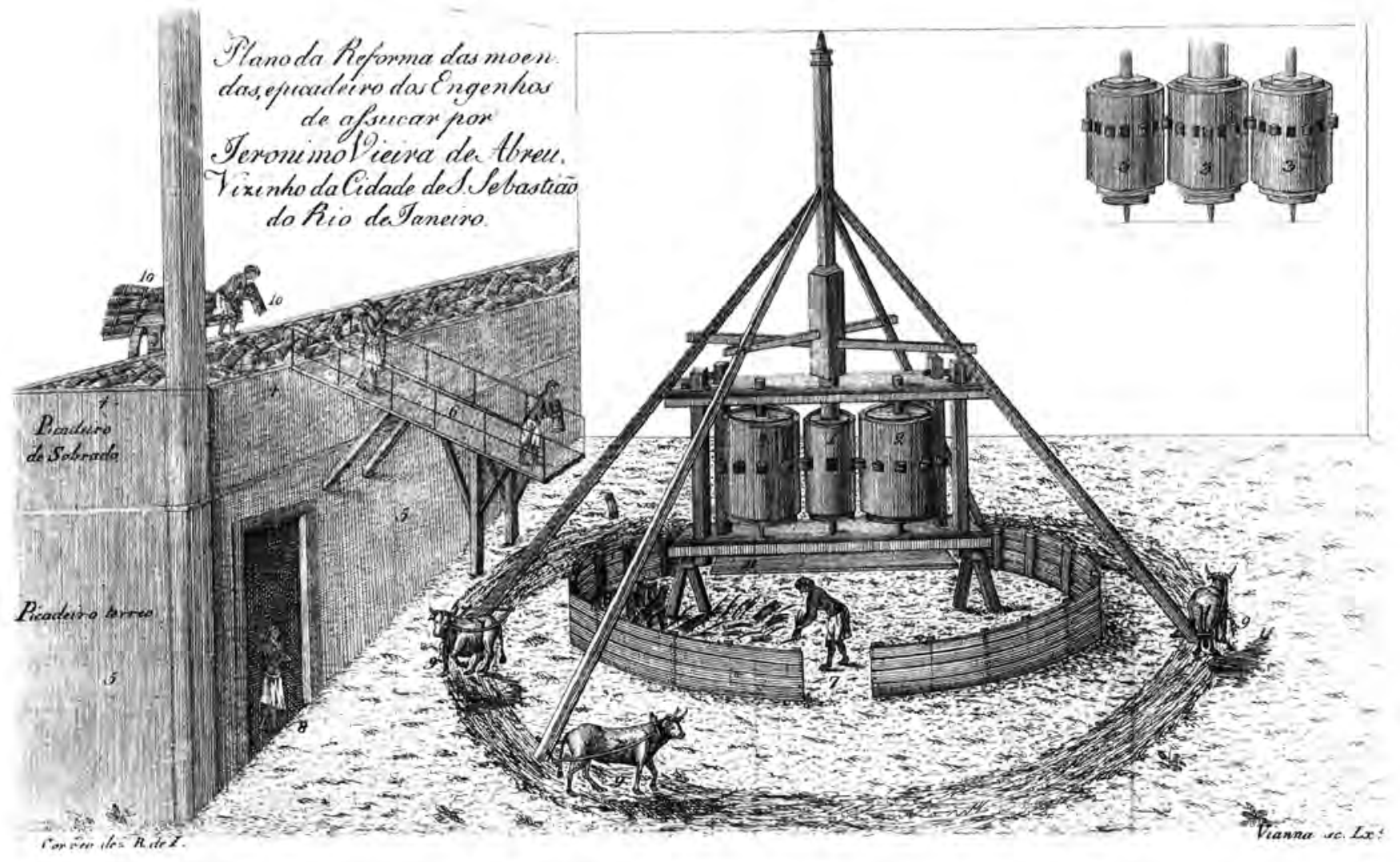

Imagem 5: "Plano da reforma das moendas dos engenhos de açúcar por Jerônimo Vieira de Abreu, vizinho da cidade de São Sebastião do Rio de Janeiro", estampa publicada por José Mariano da Conceição Veloso em O fazendeiro do Brasil, t.1, parte 1, "Da cultura das canas e da fatura do açúcar", estampa 3, 1798-1806 (Campos et al., 1999, p.235) 
do fazendeiro ao feitor e outros trabalhadores, muitos compulsoriamente envolvidos nas plantações e nas fábricas. A imagem contribuía decisivamente para a apreensão e leitura do conhecimento transmitido. Essa linguagem visual inseria-se na cultura visual da ilustração de maneira mais ampla. Essas imagens eram caracterizadas pelo emprego do desenho e da gravura, considerando a gravura uma forma moderna e contemporânea de comunicação com alta capacidade representacional.

Esses manuais circularam no mundo letrado e científico do império português e lusobrasileiro. É notável sua importância entre os letrados luso-brasileiros envolvidos com o Arco do Cego, com a engenharia militar e na história natural na corte joanina. Há uma série deles publicada pela Imprensa Régia no Rio de Janeiro entre 1808-1821. Os manuais apareciam de diversas maneiras no cotidiano letrado, fosse na escrita, na produção impressa, na leitura, no intuito de garantir e alimentar sua circulação. Manoel Ferreira de Araújo Guimarães (Carolino, 2012) publicou Elementos de geometria de A.M. Legendre em 1809, baseando-se nos trabalhos de Romão Eloi de Almeida ou Paulo dos Santos Ferreira Santos, ambos com formação na oficina do Arco do Cego (Moraes, Camargo, 1993, p.21). Naquela altura, ele era lente de matemática e capitão do Real Corpo de Engenheiros, frequentando assim e cotidianamente essa literatura de manuais. Esse mesmo Manoel Ferreira de Araújo Guimarães editou O Patriota entre 1813-1814 e publicou o seu Elementos de astronomia para uso dos alunos da Academia Real Militar (1814).

\section{Considerações finais}

Esses manuais não se restringiam à produção de material didático para um público inculto, como se fossem somente um texto introdutório e facilitador para um leitor inexperiente e tolo. Antes, ao contrário, o ensino se efetivava por meio desses manuais, porque corria com eles, quase de maneira inerente, a produção do conhecimento. Os manuais detalhavam e explicavam o processo de produção de determinado objeto - do riscado, do mapa, da fortificação, do açúcar -, a demarcação territorial, o embalar, desenhar, enviar um elemento visto e recolhido da flora e da fauna. Estavam embasados e eram informados pela síntese teórica de algum conhecimento, entremeada às suas práticas. Assim, havia uma mesma lógica a reger o fazer, o explicar, o publicar, o fazer circularem os conhecimentos estudados que eram sinteticamente apresentados nos manuais. Eles participavam ativamente de um vetor processual no aprendizado de determinada técnica, podendo inclusive afastar um leitor destreinado ou, talvez por isso mesmo, parecendo uma publicação útil que merecia ser lida, reeditada e difundida, na medida em que continha uma síntese que atuava na definição disciplinar e muitas vezes institucional de certos saberes, como, por exemplo, a engenharia militar, a história natural, a tipografia, as práticas agrícolas. Nessa direção, o manual não ficava instalado nas franjas da produção de conhecimento, fosse por ser a teoria compreendida como a fonte geradora do saber, fosse por ser elaborado no mundo português e luso-brasileiro. Ocupava um papel central na fixação dos conteúdos e das práticas desses saberes, sendo a práxis considerada uma virtude de primeira grandeza. 


\section{AGRADECIMENTOS}

Este artigo resulta do projeto "Ciência, arte e técnica: questões de cultura visual no mundo luso-brasileiro (1750-1820)", financiado pelo CNPq.

\section{REFERÊNCIAS}

ARAÚJO, Renata Malcher.

A urbanização da Amazônia e do Mato Grosso no século XVIII: povoações civis, decorosas e úteis para o bem comum da coroa e dos povos. Anais do Museu Paulista, v.20, n.1, p.41-76. Disponível em: http://www.scielo.br/scielo.php?script=sci_ arttext\&pid=S0101-47142012000100003\&lng= pt\&nrm=iso\&tlng=pt. Acesso em: 20 out. 2014. 2012.

BLUTEAU, Raphael; SILVA, Antônio Moraes da. Dicionário da língua portuguesa: composto pelo padre Rafael Bluteau, reformado e acrescentado por Antonio de Moraes da Silva, natural do Rio de Janeiro. Lisboa: Oficina de Simão Tadeu Ferreira. 1790.

BRIGOLA, João Carlos.

O colecionismo científico em Portugal nos finais do Antigo Regime, 1768-1808. In: Kury, Lorelai; Gesteira, Heloísa (Org.). Ensaios de história das ciências no Brasil. Rio de Janeiro: Eduerj. p.135152. 2012.

BRIGOLA, João Carlos.

Colecções, gabinetes e museus em Portugal no século XVIII. Lisboa: Fundação Calouste Gulbenkian. 2003.

BROTERO, Félix de Avellar.

Compêndio de botânica, ou Noções elementares desta ciência. Paris. [s.n.]. 2v. 1788.

BUENO, Beatriz P. Siqueira.

Sistema de produção da arquitetura na cidade colonial brasileira: mestres de oficio, "riscos" e "traças". Anais do Museu Paulista, v.20, n.1, p.321-361. Disponível em: http://www. scielo.br/scielo.php?script=sci_arttext\&pid =S0101-47142012000100011. Acesso em: 20 out. 2014. 2012.

BUENO, Beatriz P. Siqueira.

Desenho e desígnio: o Brasil dos engenheiros militares. São Paulo: Edusp; Fapesp. 2011.

CAMPOS, Fernanda Maria Guedes de et al. (Org.). A Casa Literária do Arco do Cego, 1799-1801. Lisboa: Biblioteca Nacional; Imprensa NacionalCasa da Moeda. 1999.

CAROLINO, Luís Miguel.

Manuel Ferreira de Araújo Guimarães, a Academia Real Militar do Rio de Janeiro e a definição de um gênero científico no Brasil em inícios do século XIX. Revista Brasileira de História, v.32, n.64, p.251-278. Disponível em:
http://www.scielo.br/scielo.php?pid=S010201882012000200014\&script=sci_arttext. Acesso em: 20 out. 2014. 2012.

COSTA, Hipólito José da.

Descrição da árvore açucareira e da sua utilidade e cultura. Lisboa: Tipografia Calcográfica,

Tipoplástica e Literária do Arco do Cego. 1800.

FARIA, Miguel Figueira de.

Da facilitação e da ornamentação: a imagem nas edições do Arco do Cego. In: Campos, Fernanda Maria Guedes de et al. (Org.). A Casa Literária do Arco do Cego, 1799-1801. Lisboa: Biblioteca Nacional; Imprensa Nacional-Casa da Moeda. p.107-137. 1999.

FERREIRA, Alexandre Rodrigues.

Método de recolher, preparar, remeter, e conservar os produtos naturais seguindo do plano, que tem concebido, e publicado alguns naturalistas, para o uso dos curiosos que visitam os sertões, e costas do mar. Res.18. Manuscrito (Arquivo Histórico do Museu Bocage, Lisboa). 1781.

FORTES, Manoel de Azevedo.

O engenheiro português. Lisboa: Oficina de Manoel Fernandes da Costa. 2v. 1728-1729.

FORTES, Manoel de Azevedo.

Tratado do modo o mais fácil e o mais exato de fazer as cartas geográficas, assim da terra como de mar, e tirar as plantas das praças, cidades e edifícios com instrumentos e sem instrumentos para servir de instrução à fábrica das cartas geográficas de história eclesiástica, e secular de Portugal. Lisboa: Oficina de Pascoal da Silva. 1722.

KANTOR, Iris; BUENO, Beatriz P. Siqueira; FERLINI, Vera L.A.

Território em rede: cartografia vivida e razão de Estado no século das Luzes. Anais do Museu Paulista. v.17, n.2, p.11-15. Disponível em: http://www.scielo.br/scielo.php?script=sci arttext\&pid=S0101-47142009000200002\&lng= pt\&nrm=is\&tlng=pt. Acesso em: 20 out. 2014. 2009.

KURY, Lorelai.

Les instructions de voyage dans les expéditions scientifiques françaises (1750-1830). Revue d'Histoire des Sciences, v.51, n.1, p.65-91. 1998.

MAGALHÃES, Joaquim Romero.

Mundos em miniatura: aproximação a

alguns aspectos da cartografia portuguesa no 
Brasil (séculos XVI a XVIII). Anais do Museu Paulista, v.17, n.1, p.69-94. Disponível em: http://www.scielo.br/scielo.php?script=sci arttext\&pid=S0101-47142009000100006\&lng=en \&nrm=iso. Acesso em: 9 jul. 2013. 2009.

MORAES, Rubens Borba de; CAMARGO, Ana Maria.

Bibliografia da Impressão Régia do Rio de Janeiro. São Paulo: Edusp; Kosmos. 1993.

PATACA, Ermelinda Moutinho.

Coletar, preparar, remeter, transportar: práticas de história natural nas viagens filosóficas portuguesas, 1777-1808. Revista Brasileira de História da Ciência, v.4, p.125-138. 2011.

PATACA, Ermelinda Moutinho.

Terra, água e ar nas viagens científicas portuguesas, 1755-1808. Tese (Doutorado em Geociências) Universidade Estadual de Campinas, Campinas. 2006.

PATACA, Ermelinda Moutinho; PINHEIRO, Rachel.

Instruções de viagem para a investigação científica do território brasileiro. Revista da Sociedade Brasileira de História da Ciência, v.3, n.1, p.58-79. 2005.
PEREIRA, Magnus R. de M.; CRUZ, Ana Lucia B. da.

Instructio peregrinatoris: algumas questões referentes aos manuais portugueses sobre métodos de observação filosófica e preparação de produtos naturais da segunda metade do século XVIII. In: Kury, Lorelai; Gesteira, Heloisa (Org.). Ensaios de história das ciências no Brasil: das Luzes à nação independente. Rio de Janeiro: Eduerj; Faperj. 2012.

SEABRA, Vicente Coelho de.

Elementos de química oferecidos à Sociedade Literária do Rio de Janeiro. Coimbra: Real Oficina da Universidade. 1788.

SCARANO, Fabio Rubio. De Vandelli para Lineu, de Lineu para Vandelli: correspondência entre naturalistas. Rio de Janeiro: Dantes. 2008.

SCHIAVINATTO, Iara Lis.

Imagens do Brasil: entre a natureza e a história. In: Jancsó, Istvan. Brasil: formação do Estado e da Nação. São Paulo: Hucitec; Unijuí. p.135-160. 2003.

VAZ, Francisco António Lourenço. Instrução e economia: as ideias econômicas no discurso da Ilustração portuguesa, 1746-1820. Lisboa: Colibri. 2002. 